\title{
Mengenal Relief, Mudra dan Stupa Candi Borobudur untuk Anak-Anak Usia 9-12 Tahun melalui Edugame
}

\author{
Ima Kusumawati Hidayat, Priyanto Sunarto \& Triyadi Guntur
}

Fakultas Seni Rupa dan Desain

Institut Teknologi Bandung, Jl. Ganesa 10, Bandung 40132

Email: ima_hidayat@yahoo.com

\begin{abstract}
Abstrak. Candi Borobudur sebagai salah satu aset budaya Indonesia dan menjadi salah satu keajaiban dunia, pertama diperkenalkan kepada anak-anak dalam mata pelajaran Ilmu Pengetahuan Sosial (IPS) di Sekolah Dasar (SD) sebagai bangunan peninggalan kerajaan Buddha di Indonesia. Pengetahuan yang diberikan sebatas pada tahun pembangunan, raja yang memimpin dan membangun, serta nama tingkatan pada candi. Pemberian pelajaran di sekolah tidak hanya dari buku, namun dapat dilakukan dengan pendekatan multimedia. Berdasarkan hasil penelitian yang dilakukan kepada anak-anak usia 9-12 tahun, guru pelajaran IPS dan pemandu wisata Candi Borobudur yang memberi materi kepada anak-anak ketika berkunjung. Candi Borobudur tidak dapat dipisahkan dari relief-reliefnya yang indah, arca Buddha yang memiliki berbagai sikap tangan (mudra) dan stupa Candi Borobudur menjadi materi yang perlu diberikan kepada anak-anak karena belum didapatkan di sekolah. Memberikan pendekatan yang berbeda dalam mempelajari suatu pengetahuan baru dapat memudahkan anak-anak untuk menyerap teori baru namun dengan cara yang lebih menyenangkan. Memadukan game dengan ilmu pengetahuan menjadi edugame merupakan salah satu cara untuk menyiasati anak-anak agar tetap belajar sambil bermain.
\end{abstract}

Kata kunci: anak-anak; Candi Borobudur; edugame.

\begin{abstract}
Borobudur Temple is one of the world heritage from Indonesia that being introduced to Indonesian student in history lesson at elementary school. But the national curriculum doesn't give all children needs because they should learn lot of lessons from history. Different knowledge of Borobudur Temple can be given to children by video game, because as a student, children want to spend their leisure time at home with something they like most. The knowledges that will be given to children are based on the research from children, 9-12 years old, their teachers, and tourist guide who gave the children some knowledge when they come to Borobudur temple. The main of Borobudur temple are it beautiful reliefs, Buddha's hand positions and stupa. Creating game with education is a one great way to help children learn about Borobudur temple, so they will get new knowledge and fun.
\end{abstract}

Keywords: Borobudur Temple; children; edugame.

Received September $3^{\text {rd }}, 2012$, Revised January $16^{\text {th }}, 2014$, Accepted for publication January $16^{\text {th }}, 2014$. Copyright () 2014 Published by LPPM ITB, ISSN: 1978-3078, DOI: 10.5614/itbj.vad.2014.6.1.6 


\section{$1 \quad$ Pendahuluan}

Berakhirnya zaman prasejarah di Indonesia ditandai dengan datangnya bangsa dan pengaruh Hindu yang diikuti masuknya agama Buddha ke Indonesia pada masa kerajaan Sriwijaya. Agama Buddha sampai ke Asia Tenggara sebagai akibat aktivitas kolonisasi umat Hindu yang bukan saja mendirikan pusat-pusat perdagangan tapi juga membawa serta cara pemujaan dan kebudayaan mereka. Kehadiran dua agama tersebut meninggalkan banyak kekayaan budaya berupa candi, salah satunya adalah candi megah agama Buddha, Candi Borobudur.

Candi Borobudur dipercaya sebagai perwujudan dari kitab suci yang berisi cerita-cerita tentang dewa, kehidupan manusia, hewan, dan perwujudan 'Boddhisatva' yang diarahkan sebagai monumen atas intisari kehidupan dari dasar hingga puncak bangunan. Kemegahan Candi Borobudur menjadikannya salah satu tujuan wisata para turis lokal maupun internasional sehingga menjadi aset kebanggaan Indonesia. Bersama dengan situs manusia purba Sangiran dan Candi Prambanan, Candi Borobudur menjadi situs warisan dunia UNESCO dari Indonesia yang dikategorikan dalam World Heritage of Culture yang harus dilestarikan [1].

Pengetahuan mengenai relief, arca patung Buddha beserta stupa yang merupakan bangunan inti dari Candi Borobudur belum mendapat porsi dalam pelajaran siswa SD, namun pengetahuan di luar dari yang telah diberikan di sekolah dapat menjadi potensi yang baik agar anak-anak mengetahui berbagai hal dari Candi Borobudur, seperti penjelasan-penjelasan yang didapatkan dari pemandu wisata di Candi Borobudur. Pemandu wisata Candi Borobudur membagi pengetahuan yang diberikan kepada pengunjung sesuai dari usia dan pendidikan. Anak-anak akan mendapatkan pengetahuan yang lebih sederhana daripada pengetahuan yang dipaparkan kepada mahasiswa.

Cerita tentang makna relief, arti dari sikap tangan (mudra) arca Buddha dan bentuk stupa yang indah dapat menjadi sangat menarik dan disukai anak-anak. Belajar tentang bangunan bersejarah tidak hanya pada tahun pembuatan, nama raja yang berkuasa, atau letak bangunan tersebut, namun anak-anak dapat belajar dari sisi lain yang lain dan tidak kalah menarik.

Game sebagai media baru dapat menjadi sebuah solusi memadukan pelajaran yang serius dengan permainan yang menyenangkan. Perpaduan tersebut disebut sebagai edugameledutainment. Konsep dari edugame adalah mengajak pemain untuk bermain namun secara tidak langsung mendapatkan pengetahuan diluar kesadarannya. Anak-anak akan tetap mendapatkan pengetahuan tambahan selain yang telah didapatkan di sekolah, namun mereka juga tetap mendapatkan kesenangan dari permainan edugame. 
Anak usia 9-12 tahun yang beranjak remaja, mulai mengurangi jam bermain diluar rumah karena tanggung jawab di sekolah lebih besar. Mereka memilih untuk bermain dirumah dan memilih game sebagai salah satu media hiburan menghilangkan kepenatan. Banyak orang dewasa menganggap waktu yang dihabiskan anak dengan hiburan sebagai pemborosan waktu dan akan lebih banyak mendapat faedah dari bermain aktif [2], sehingga menyiratkan bahwa game dianggap tidak memperluas pergaulan sosial anak dan penyesuaiannya pada lingkungan.

\section{Candi Borobudur}

Candi, menurut Hardiati ES [3] adalah peninggalan arsitektural yang berasal dari masa klasik Indonesia yaitu masa berkembangnya kebudayaan yang berlatar belakang agama Hindu dan Buddha, dari abad ke-5 M sampai ke-15 M. Bangunan candi memiliki wujud triangga yaitu kepala, badan dan kaki (Lihat Gambar 1). Masing-masing bagian ini memiliki arti secara simbolis yaitu kepala melambangkan alam atas, yang merupakan alam para dewa; badan melambangkan alam antara yang mempunyai makna sebagai tempat manusia yang telah meninggalkan tempat suci; dan kaki yang melambangkan alam bawah yaitu tempat manusia biasa. Beberapa peninggalan bersejarah tersebut adalah Candi Prambanan dari kerajaan Hindu dan Candi Borobudur dari kerajaan Buddha. Kegunaan candi adalah sebagai tempat pemujaan dewa oleh agama Hindu atau Buddha dan tempat disemayamkannya raja atau pemuka agama.

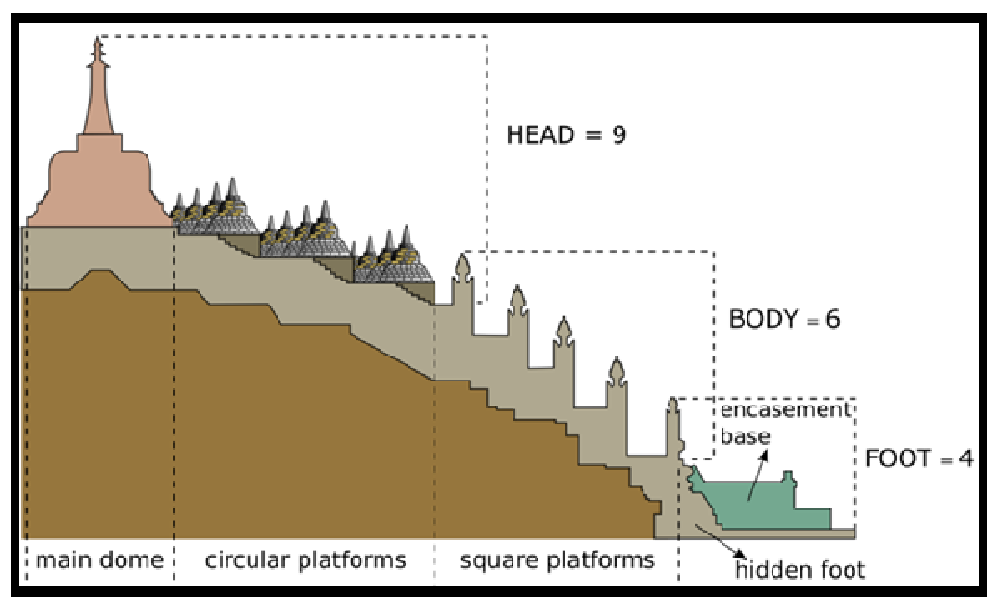

Gambar 1 Tingkatan Candi Borobudur, Sumber: http://www.kaskus.us/show post.php, (12 September 2011). 
Berikut merupakan 3 bagian dari Candi Borobudur yang menjadi objek pada penilitian ini:

1. Relief Candi Borobudur

Relief pada Candi Borobudur memiliki makna dan cerita tersendiri. Setiap panelnya tersirat berbagai macam bentuk seperti bentuk manusia, hewan, tumbuhan, bahkan kendaraan masa lalu. Relief Candi Borobudur terdiri dari relief Lalitavistara, relief Jataka- Awadana, dan relief Gandawyuha.

2. Mudra Arca Buddha Candi Borobudur

Arca Buddha dalam relung-relung di tingkat Rupadhatu, diatur berdasarkan barisan di sisi luar pagar langkan. Jumlahnya semakin berkurang pada sisi atasnya. Barisan pagar Langkan pertama terdiri dari 104 relung, baris kedua 104 relung, baris ketiga 88 relung, baris keempat 72 relung, dan baris kelima 64 relung. Jumlah total terdapat 432 arca Buddha di tingkat Rupadhatu. Dari lapisan pertama sampai keempat terdapat patung-arca Dhyani Buddha (masing-masing 92 buah) yang setiap sisi memiliki perbedaan sikap tangan atau mudra, merupakan 6 sikap tangan Buddha yang terdapat pada Candi Borobudur (Lihat Tabel 1).

3. Stupa Candi Borobudur Jumlah stupa 73 buah dengan rincian 1 buah stupa induk, 32 stupa pada teras melingkar I, 24 stupa pada teras melingkar III, dan 16 stupa pada teras melingkar IIII. Terdapat 3 macam bentuk stupa (Lihat Gambar 2):

a. Stupa induk berongga, tanpa lubang terawang pada puncak candi;
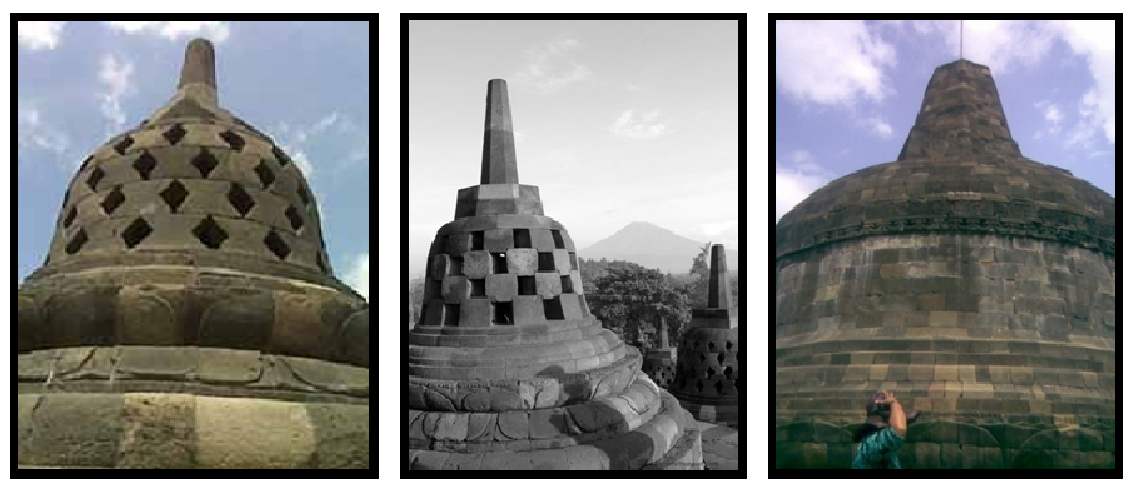

Gambar 2 (a) Stupa dengan Lubang Ketupat. Sumber: http://www. riyantoyosapat.com/arsitektur/ (b) Stupa Tanpa Lubang. Sumber: http://tamansaya.blogspot.com/2011/. (c) Stupa dengan Lubang Bujur Sangkar. Sumber: http://fandyjayanto.blogspot.com/2011/04/blog-post_09.html. (21 November 2011) 
Tabel 1 Mudra Arca Buddha pada Candi Borobudur. Sumber gambar: Museum Karmawibhangga Candi Borobudur, Jawa Tengah. (keterangan makna) [4].

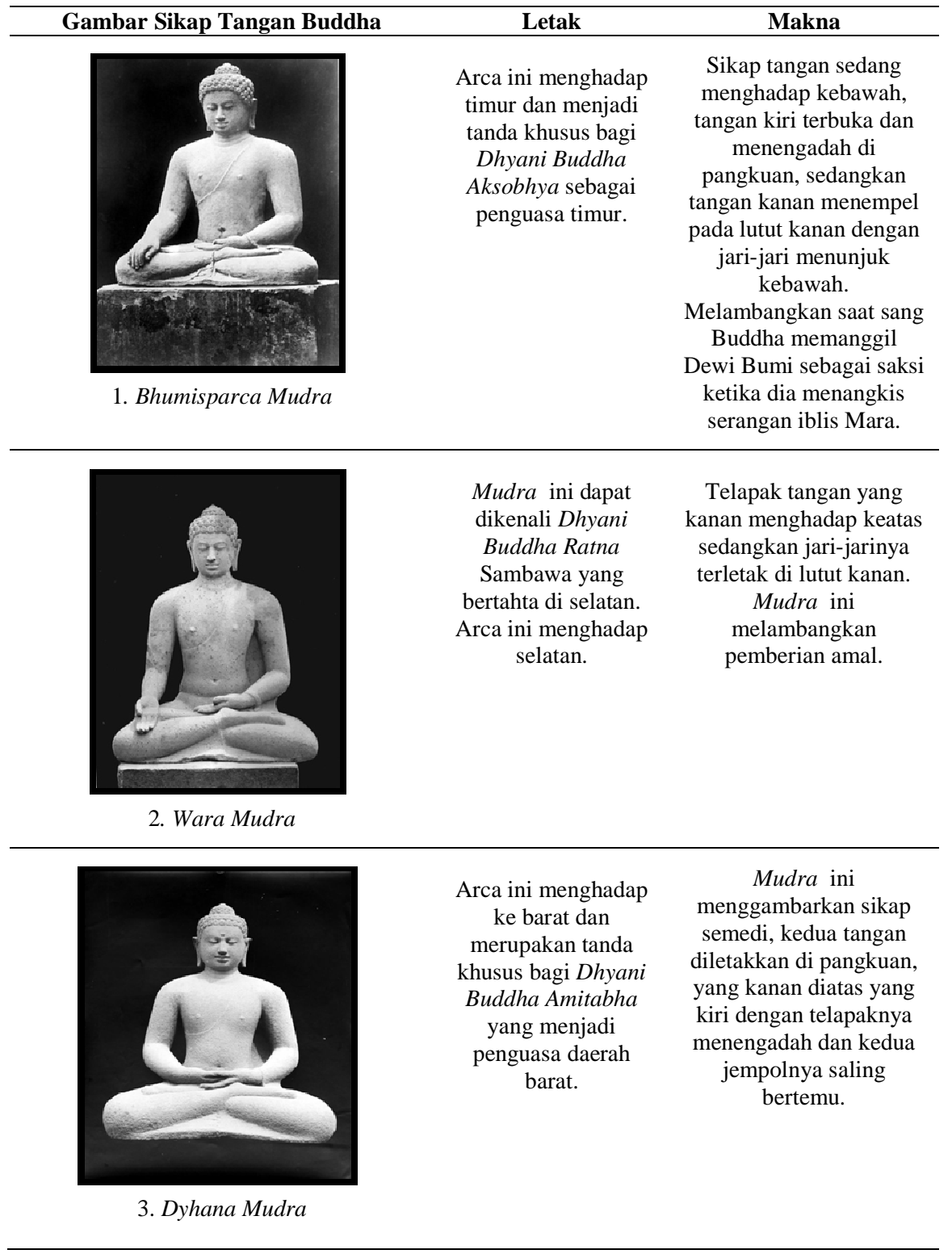




\begin{tabular}{|c|c|c|}
\hline Gambar Sikap Tangan Buddha & Letak & Makna \\
\hline & $\begin{array}{l}\text { Arca ini menghadap } \\
\text { ke utara Langkan } \\
\text { dan merupakan tanda } \\
\text { khusus bagi Dhyani } \\
\text { Buddha Amogasidha } \\
\text { yang berkuasa di } \\
\text { utara. }\end{array}$ & $\begin{array}{c}\text { Tangan kiri terbuka dan } \\
\text { menengadah di } \\
\text { pangkuan, tangan kanan } \\
\text { diangkat sedikit diatas } \\
\text { lutut kanan dengan } \\
\text { telapak menghadap } \\
\text { muka. } \text { Mudra ini } \\
\text { menggambarkan sikap } \\
\text { tangan sedang } \\
\text { menenangkan dan } \\
\text { menyatakan ketidak } \\
\text { gentaran. }\end{array}$ \\
\hline
\end{tabular}

4. Abhaya Mudra

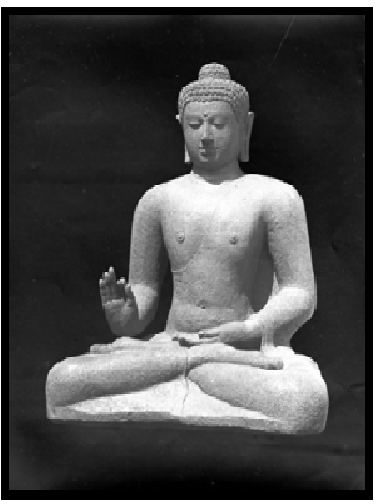

Mudra ini menjadi ciri khas bagi Dhyani Buddha

Waroicana.Arca ini terdapat di tengah, pada tingkat

Rupadhatu di pagar langkan baris kelima (teratas).
Tangan kiri terbuka dan menengadah di pangkuan, sedangkan tangan kanan diangkat sedikit diatas lutut kanan dengan telapak menghadap muka, jari telunjuk dan ibu jari bersatu. Mudra ini menggambarkan akal budi.

5. Witarka Mudra

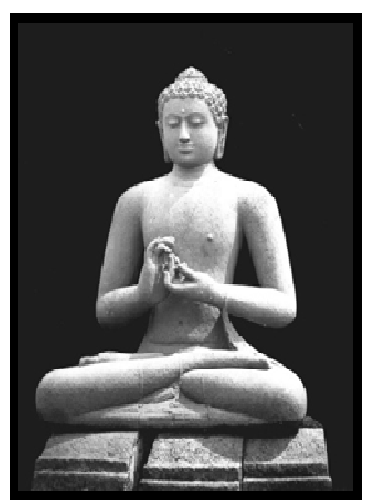

Mudra ini menjadi ciri khas bagi Dhyani Buddha Waroicana yang daerah kekuasaannya terletak di pusat.
Kedua tangan diangkat sampai ke depan dada, yang kiri dibawah yang kanan. Tangan kiri menghadap ke atas dengan jari manisnya, serupa dengan gerakan memutar roda. Mudra ini melambangkan gerak memutar roda dharma.

6. Dharmacakra Mudra 
b. Stupa pada teras melingkar berlubang belah ketupat pada stupa teras melingkar I dan II;

c. Stupa pada teras melingkar berlubang segi empat pada stupa teras melingkar III.

Arti simbolis lubang terawang belah ketupat berkaitan dengan filosofi menuju ke tingkat kesempurnaan, sedangkan arti simbolis lubang terawang segi empat berkaitan dengan filosofi lebih sempurna daripada bentuk belah ketupat yang masih tergolong raya. Stupa puncak yang tidak memiliki lubang terawang dimaknakan sebagai nirwana, puncak dari kehidupan.

\section{Perkembangan Anak Usia 9-12 Tahun}

Masa kanak-kanak menengah akhir (usia 9-12 tahun) adalah masa dimana anakanak lebih siap belajar dan mulai mengurangi khayalan imajinasi mereka. Menurut Santrock [5] anak-anak mengembangkan perasaan untuk membuat sesuatu yang baik dan sempurna. Orang tua memiliki peranan penting dalam hidup mereka, namun teman sebaya dan lingkungan mempengaruhi perkembangannya. Pada usia ini, orang tua dapat lebih mengarahkan anak-anak pada media baru yang dapat mereka terima. Semakin banyak media yang ada perlu adanya filter dari orang tua agar hal positif dari perkembangan teknologi dapat diterima baik oleh anak-anak.

\section{$4 \quad$ Edu Game}

Edu game tidak masuk dalam core genre (tipe game utama). Game ini biasanya dikategorikan sebagai game lain atau uncategorized games. Beberapa mengkategorikan edu game sebagai serious game karena permainannya tidak sepenuhnya untuk fun atau bersenang-senang [6]. Ada unsur lain dari edu game yang bukan sekedar menghibur (entertainment), sehingga seringkali disebut edutainment. Edu game dibuat dengan tujuan spesifik sebagai alat pendidikan, entah untuk belajar mengenal warna untuk balita, mengenal huruf dan angka, matematika, sampai belajar bahasa asing. Game designer harus memperhitungkan berbagai hal agar game ini benar-benar dapat mendidik, menambah pengetahuan dan meningkatkan ketrampilan yang memainkannya. Target segmentasi pemain harus pula disesuaikan dengan tingkat kesulitan dan desain visual ataupun animasinya. Contoh edugames: Bobi Bola, Dora The Explorer, Petualangan Billy dan Tracy (lihat Gambar 3). 

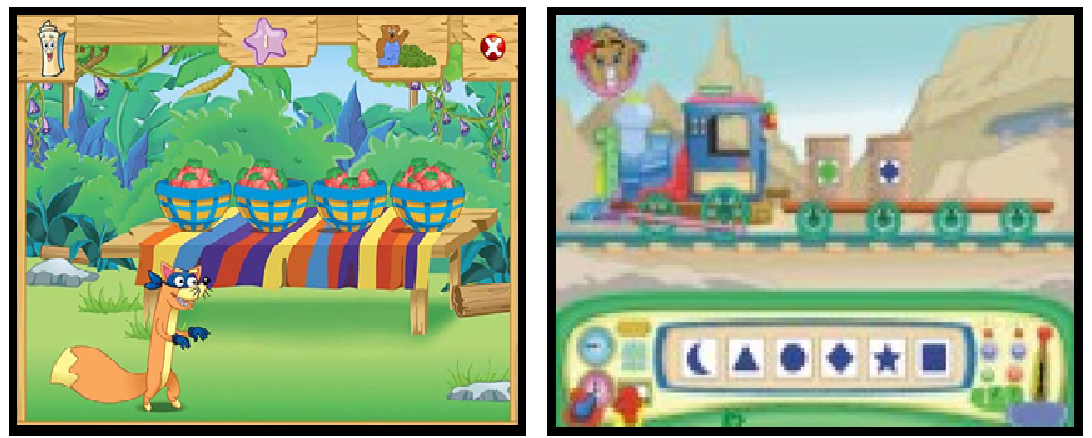

Gambar 3 Kiri: Edugame Dora The Explorer. Sumber:http://www.downloadgame-demo.com/imgs/dora-the-explorer; Kanan: Edugame Bobi Bola. Sumber: http://img1.tokobagus.com/22/49/2222491_9618563.jpg. Diunduh 3 April 2012.

\section{Perancangan Game}

Saat ini perkembangan games di komputer sangat cepat. Para pengelola industri game berlomba-lomba untuk menciptakan game yang lebih nyata dan menarik untuk para pemainnya. Hal inilah yang membuat perkembangan games di komputer sangat cepat. Bermain games bukan hanya sekedar untuk mengisi waktu luang atau sekedar hobi, melainkan sebuah cara untuk meningkatkan kreatifitas dan tingkat intelektual para penggunanya karena suatu proses fine tuning (atau penyamaan frekuensi) dari logika berpikir anak-anak dengan logika berpikir aplikasi komputer yang canggih tadi. Pada saat bersamaan, game juga secara nyata mempertajam daya analisis para penggunanya untuk mengolah informasi dan mengambil keputusan cepat yang jitu. Ketika game memiliki muatan edukasi, pemain terkadang tidak sadar mendapatkan pengetahuan secara tidak langsung karena bermain game sangat menyenangkan dan beranggapan bahwa game hanya sebagai hiburan.

Game Dooland adalah game bergenre puzzle dengan konten yang dipilih adalah mengenalkan ragam bentuk ornamen dari Candi Borobudur, relief satwa dan tumbuhan, mudra Buddha dan ragam bentuk rongga stupa. Pemilihan nama game Dooland dalam perancangan ini berdasarkan pada bahasa Inggris, Doo (dari do) berarti bekerja, melakukan sesuatu hal dan Land adalah tanah, wilayah. Sehingga ketika diartikan menjadi wilayah yang harus diselesaikan (dikerjakan), yaitu pemain harus mencocokkan berbagai ikon untuk mendapatkan pengetahuan yang dijanjikan oleh Bhara dan Wardhani. Ketika dilafalkan dalam bahasa Indonesia menjadi dolan yang dalam bahasa Jawa berarti bermain. Kata Doo digunakan sebagai singkatan dari Borobudur, sedangkan Land adalah kumpulan huruf yang diambil dari beberapa kata berikut, L dari relief, A dari stupa, dan ND dari patung Buddha 
Tabel 2 Interface Game Dooland.

\begin{tabular}{|c|c|c|}
\hline Interface Game Dooland & Penerapan & Keterangan \\
\hline & Menu utama & $\begin{array}{l}\text { Memilih } 3 \text { opsi, yaitu pilihan, } \\
\text { bermain dan keluar }\end{array}$ \\
\hline Hai,aku Bhara & Cerita awal 1 & $\begin{array}{c}\text { Bhara dan Wardhani } \\
\text { memperkenalkan diri kepada } \\
\text { pemain }\end{array}$ \\
\hline & Cerita awal 2 & $\begin{array}{c}\text { Bhara bercerita kepada Wardhani } \\
\text { bahwa ia baru saja mengunjungi } \\
\text { Candi Borobudur }\end{array}$ \\
\hline & Cerita awal 3 & $\begin{array}{l}\text { Bhara dan Wardhani bercakap- } \\
\text { cakap }\end{array}$ \\
\hline & Cerita Awal 4 & $\begin{array}{c}\text { Bhara mengagumi relief Candi } \\
\text { Borobudur }\end{array}$ \\
\hline $\begin{array}{l}\text { lief di Candi Borobudur } \\
\text { ngat indah... }\end{array}$ & & \\
\hline
\end{tabular}




\begin{tabular}{|c|c|c|}
\hline Interface Game Dooland & Penerapan & Keterangan \\
\hline & Cerita Awal 5 & $\begin{array}{c}\text { Bhara baru mengetahui jika sikap } \\
\text { tangan arca Buddha berbeda-beda, } \\
\text { Wardhani menimpali }\end{array}$ \\
\hline & Cerita Awal 6 & $\begin{array}{c}\text { Bhara berusaha meraih Kunto } \\
\text { Bimo di dalam stupa Candi } \\
\text { Borobudur }\end{array}$ \\
\hline $\begin{array}{l}\text { atau memegang Kunto Bimo } \\
\text { yang aded did dalam stupa.. }\end{array}$ & & \\
\hline 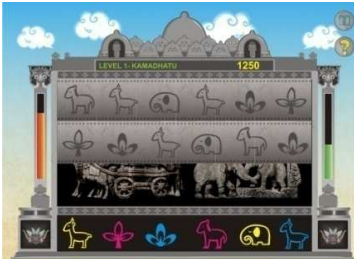 & $\begin{array}{l}\text { Interface } \\
\text { Level } 1\end{array}$ & $\begin{array}{c}\text { Penampakan level } 1 \text { dengan langit } \\
\text { siang hari yang cerah. Ketika } \\
\text { pemain dapat menyelesaikan } \\
\text { permainan, mendapatkan reward } \\
\text { berupa potongan relief Candi } \\
\text { Borobudur. }\end{array}$ \\
\hline
\end{tabular}

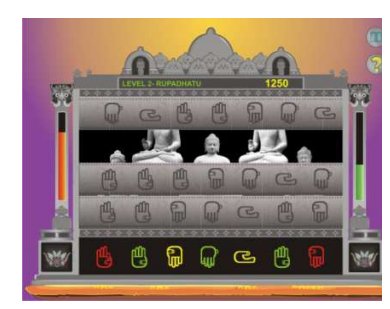

Interface

Penampakan level 2 dengan langit sore hari menjelang matahari

Level 2 terbenam. Ketika pemain dapat menyelesaikan permainan, mendapatkan reward berupa arca Buddha dengan berbagai sikap tangan.

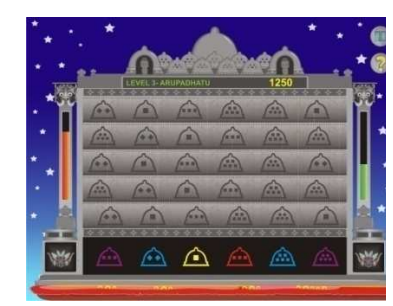

Interface

Penampakan level 3 dengan langit malam hari yang bertamburan

level 3 bintang. Ketika pemain dapat menyelesaikan permainan, mendapatkan reward berupa 3 macam bentuk stupa Candi Borobudur.

Konsep utama yang diusung adalah easy and fun, sehingga siapa saja dapat dengan mudah memahami alur permainan. Konsep easy and fun kemudian akan 
menjadi dasar dari konsep visual game karena target audience game Dooland adalah anak-anak usia 9-12 tahun sehingga banyak ragam warna yang digunakan. Pendekatan yang dilakukan adalah perancangan game yang bermuatan edukasi namun disajikan dengan menarik sehingga anak-anak secara tidak sadar belajar sambil bermain.

Membuat interface dalam game adalah hal yang tidak mudah karena interface mengkomunikasikan berbagai macam hal dari game kepada pemain. Interface menjadi perantara pemain dan game. Pemain game akan menilai menarik atau tidaknya sebuah game dari desain interface sebelum benar-benar memainkan game itu sendiri. Beberapa visual interface game Dooland, dapat dilihat pada Tabel 2, menunjukkan materi game yang diberikan.

\section{$6 \quad$ Kesimpulan}

Pendekatan media baru berupa edugame kepada anak-anak usia 9-12 tahun untuk mempelajari Candi Borobudur merupakan suatu cara yang baik karena seringkali anak-anak tidak ingin belajar kesejarahan diluar yang telah didapatkan di sekolah, sedangkan di rumah mereka ingin terus bermain game untuk menyegarkan pikiran dari kepenatan di sekolah. Pengenalan relief, mudra dan stupa Candi Borobudur dapat meningkatkan kecintaan anak-anak pada peninggalan budaya Indonesia, serta menimbulkan rasa empati dan peduli.

\section{Referensi}

[1] Unesco \& National Geographic Indonesia. 2011. Borobudur: The Road to Recovery-Rehabilitation Work and Sustainable Tourism Development, $\mathrm{p}$. 18.

[2] Hurlock, E.B. 1978. Perkembangan Anak Jilid 1, Jakarta: Penerbit Erlangga.

[3] Hardiati, E.S. \& Siagian, R. 2002. Candi Sebagai Warisan Seni dan Budaya Indonesia, Yogyakarta: Yayasan Cempaka Kencana.

[4] Marzuki, Y. \& Heraty, T. 1989. Borobudur, Jakarta: PT Djambatan.

[5] Oxland, Kevin. 2004. Gameplay and Design, Essex: Pearson Education Limited.

[6] Santrock, J.W. 2011. Masa Perkembangan Anak (Buku 2), Jakarta: Salemba Humanika. 